\title{
Evaluasi Bayi yang Lahir dari Ibu Preeklampsia dan Eklampsia
}

\author{
Immanuel Mustadjab
}

Telah dilakukan penelitian retrospektif pada bayi-bayi yang lahir dari ibu penderita preellampsia dan eklampsia (PEE) di Subbagian Perinatologi IKA/RSUP Manado antara bulan Januari sampai Desember 1998. Selama tahun 1998 telah lahir 2717 bayi di kamar bersalin Bagian Kebidanan dan Penyakit Kandungan RSUP Manado dan 84 (3,1\%) di antaranya lahir dari 79 ibu penderita PEE, 5 orang dari ibu penderita PEE tersebut melahirkan kembar dua. Usia ibu penderita PEE berkisar antara 15-45 tahun, sebagian besar yakni 22 ibu $(27,85 \%)$ berusia antara 30-34 tahun. Jumbh kehamilan berkisar antara 1-8 kali dan sebagian besar merupalcan primigravida yaitu 42 atau $53,16 \%$. Dibandingkan dengan ibu yang tidak menderita PEE, ibu penderita PEE 4,4 kali lebih sering melahirkan bayi KMK, dengan asfiksia berat sebanyak $26,19 \%$ dan berat lahir rendah sebanyak 33,33\% (p<0,05). Persalinan terbanyak melalui bedah kaisar $(53,57 \%)$. Bayi-bayi yang lahir dari ibu penderita PEE tersebut scbagian besar mengalami IUFD $(40 \%)$. Kematian tertinggi bayi yang lahir dari ibu penderita PEE disebabkan oleh pneumonia $(20 \%)$.

Kata kunci: preeklampsia-eklampsia, berat badan lahir rendah, asfiksia.

P re-eklampsia dan eklampsia (PEE) tidak hanya merupokan masalah pada ibu hamil, akan tetapi juga merupakan penyebab penting dari kesakitan dan kematian ibu dan janin.' Hal ini disebablean oleh vasospasme arteriola umum sehingga menimbulkan perdarahan, infark, nekrosis dan trombosis pembuluh darah di berbagai alat tubuh ibu hamil. ${ }^{2}$ Sedangkan pada plasenta terjadi spasme arteriola spiralis desidua yang mengakibatkan alinan darah ke plasenta berkurang. Keadaan ini mengakibatkan gangguan pertumbuhan dan perkembangan janin dan meningkatkan morhiditas dan mortalitas perinatal. ${ }^{3}$

Penyebab pre-eklampsia belum dapar dipastikan sampai kini. Ada yang berpendapat bahwa pre-

Alemar keneapandenai:

Dr. Imananel Musabjabs Sp.AIX:

Fagian Ilau Kexcheon Anak FX. UNSRAT/ BSUT Manada. JI. Faya Tanah Wanpos, Mavato 95119.

Td. 0431-53191/nsocos, Fux. 0491-859091 eklampsia disebabkan karena kekurangan prostasiklin yang berpengaruh pada penurunan reaktivitas vaskular, sehingga menimbulkan penurunan end didstolic blaod flow yang merangsang peningkatan renin dan menimbulkan vasoloonstriksi. Akibar dari vasokonstriksi terjadilah penurunan volume darah ke uterus yang mengakibarkan perkembangan janin terhambat.

Pre-eklampsia berhubuogan dengan angka kemarian dan kesakitan perinatal, retardasi pertumbuhan intra uterin dan kelahiran prematur.' Dengan segala morbiditas akibar prematuritas, dan mungkin pula lahir bayi kecil untuk masa kehamilan atau besar untuk masa kehamilan dengan berbagai morbiditasnya, seperti asfilssia, sindrom gawat napas, hiperbilirubinemia, hipoglikemia, dan lain-lain. ${ }^{2}$ Puda penclitian ini akan dilaporkan beberapa morbiditas dan mortalitas neonaus dari ibu penderita PEE yang lahir di Bagian Kebidanan dan Penyakit Kandungan RSUP Manado dan dirawar di ruang perawatan neonatus selama tahun 1998. 
Sari Pediatri, Vol. 3, No. 1, Juni 2001

\section{Bahan dan Cara}

Penelitias ini dilakukan secara retrospektif yaitu dengan mengumpulkan data dari catatan medik Subbaģian Perinatologi IKA/RSUP Manado dari bulan Januari sampai bulan Desember 1998. Data yang dicatat mencakup umur ibu, cotak paritas, ibu bamil yang menderita PEE, cara persalinan, berat lahir, morbiditas dan mortalitas neonatus selama dirawat. Diagnosis ditegakkkan secara klinis. Pemeriksaan laboratorium dan pemeriksaan lainnya banya dikerjakan aras indikasi, karena kesukaran reknis dan masalah biaya.

\section{Hasil}

Selama tahun 1998 telah lahir 2717 bayi di kamar bersalin Bagian Kebidanan dan Penyakit Kandungan RSUP Manado dan $84(3,1 \%)$ di antaranya lahir dari

Tabel 1. Jumlah ibu hamil yang menderita PEE berdararkan umur ibu

\begin{tabular}{lcr}
\hline Umar Ibu (tahua) & Jumlah & $\%$ \\
\hline$<20$ & 7 & 8,9 \\
$20-24$ & 13 & 16,5 \\
$25-29$ & 18 & 22,8 \\
$30-34$ & 22 & 27,9 \\
$>35$ & 19 & 24,1 \\
Total & 79 & 100,0 \\
\hline
\end{tabular}

ibu PEE. Delapan puluh empar bayi ini dilahirkan oleh 79 orang ibu PEE (5 dari ibu PEE melahirkan kembar dua). Umur ibu berkisar antara 15-45 tahun dengan kelompok umur terbanyak antara 30-34 thun yaitu 22 orang ibu $(27,85 \%$ ) (Tabel 1). Jumlah kehamilan berkisar antara 1-8 kehamilan, sebagian besar yakni $43(53,16 \%)$ merupakan primigravida (Tabel 2).

Thu dengan PEE lebih sering melahirkan bayi kecil untuk masa kehamilan (KMK) yaitu $20,2 \%$; bayi berar lahir rendah (BBLR) 33,30\% dan asfiksia berat $26,1 \%$. Cara persalinan yang terbanyak adalah dengan bedah kaesar $(53,6 \%)$ dan sebagian besar bayi dari ibu PEE mengalami IUFD sebesar $40 \%$. Mortalitas bayi dari ibu PEE rerringgi disebabkan oleh pneumonia $20 \%$.

Pada Tabel 3 tampak bahwa bayi besar untuk masa kehamilan (BMK) pada kelompok ibu PEE (+) dan PEE (-) proporsinya bampir sama. Sedangkan pada bayi yang sesuai untuk masa kehamilan (SMK) pada kelompok PEE (t) lebih sedikit daripada

Tabel 2, Jumlah ibu bamil yang menderita PEE. berdasarkan cocak paritas

\begin{tabular}{lcc}
\hline Jumlah kchamilan & Jumlah & $\%$ \\
\hline 1 & $\mathbf{1 2}$ & 53,2 \\
2 & 15 & 19 \\
3 & 9 & 11,4 \\
$>4$ & 13 & 16,5 \\
Tibal & 79 & 100,0 \\
\hline
\end{tabular}

Tabel 3. Sebaran Neonatus Menurut BB - Gestasi pada Kelompok PEE (t) dan PEE (-)

\begin{tabular}{|c|c|c|c|c|c|c|c|c|}
\hline \multirow{3}{*}{ PEE } & \multicolumn{8}{|c|}{ BB-gestai } \\
\hline & \multicolumn{2}{|c|}{ BMK } & \multicolumn{2}{|c|}{$5 M K$} & \multicolumn{2}{|c|}{ KMK } & \multicolumn{2}{|l|}{ Total } \\
\hline & Jumlah & $\%$ & Jumlah & $\%$ & Junnlah & $\%$ & Jumlah & $\%$ \\
\hline (4) & 3 & 3.6 & $G i$ & 76,2 & 17 & 20,2 & 84 & 100 \\
\hline$(-)$ & 54 & 2,1 & 2458 & 93.4 & 121 & 4,6 & 2633 & 100 \\
\hline
\end{tabular}

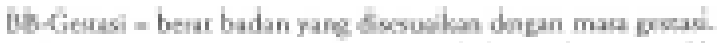

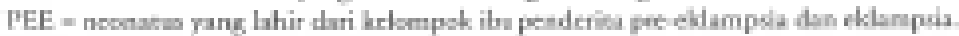

BMK = noonanus yang besar uneak mus brhimilan.

SMK - noonatus yang sesaci untuk misa kehumilan.

K.MK = neonasu yang kecil untuk mas kehanilan. 
kelompok PEE (-), dan bayi rang kecil untuk man kehamilan (KMK) pada kelonpol PEE $(+)$ terdapat 4,4 kili lebih banyk daripada kelompok PEE (-) Ibu yang menderita PEE recara bermakna lebih sering melahirkan bayi KMK (pa0,05). Tabel 5 memperlihatkan bahas bayi dari ibu dengan PEE lebih sering menderita sfiksia berat daripadi asfiksia ringan andang. Tabel 6 memperliharkan berar hhir baydari ibu dengan PEE terbanyak pada kelompok berat $2500-2999$ gram- Tabel 7 memperliharkan bahoa jumlah byi dengan bectat lair 42500 gram yang bahir dari ibu PEE (4) lebih tingei daripada ibu yang PEE $(-)$ yang seara staristile bermakna $(\mathrm{ped} 0,05)$. Tabel 8 memperlihurkan bayi dengan berat lahir uc2500gram yang lahir dari ibu PEE (+) yang meninggal lebih
Tabel 6. Stbunn Bera Lahir Bow dari Ibu PEE.

\begin{tabular}{lrr}
\hline Berar lahir (prim) & Jumlah & \\
\hline $500-59$ & 2 & 2,4 \\
$1000-1499$ & 4 & 4,8 \\
$1500-1999$ & 6 & 7,1 \\
$2000-2499$ & 16 & 19,1 \\
$2500-2999$ & 28 & 33,3 \\
$3000-3499$ & 18 & 21,4 \\
$3500-399$ & 7 & 8,3 \\
3000 & 3 & 3,6 \\
\hline Jumlah & 84 & 100,00 \\
\hline
\end{tabular}

Tabel 4. Sotwen Cara teralinan

\begin{tabular}{|c|c|c|c|c|c|c|c|c|c|c|c|c|}
\hline \multirow{3}{*}{ PEE } & \multicolumn{12}{|c|}{ Cara persalinan } \\
\hline & \multicolumn{2}{|c|}{$\mathrm{SP}$} & \multicolumn{2}{|c|}{$\mathrm{EV}$} & \multicolumn{2}{|c|}{$\mathrm{ED}$} & \multicolumn{2}{|c|}{$\mathrm{BK}$} & \multicolumn{2}{|c|}{ Whi } & \multicolumn{2}{|c|}{ Tatal } \\
\hline & Janl & 5 & Jml & 8 & Jmi & 4 & Jinl & 4 & $\mathrm{Jm}$ & $\mathrm{H}$ & Iml & ys \\
\hline$(+)$ & 9 & 107 & 12 & 4,2 & 15 & 17.9 & 45 & 53,6 & 3 & 36 & 84 & 100 \\
\hline$(-)$ & 2089 & 79,3 & 82 & 3,1 & 17 & 0.7 & 342 & 12,6 & 113 & 43 & 2633 & 100 \\
\hline
\end{tabular}

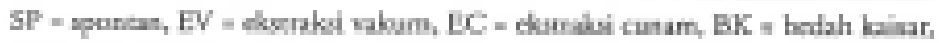
Bim - Brohomasi.

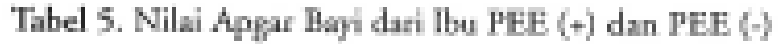

\begin{tabular}{|c|c|c|c|c|c|c|c|c|}
\hline \multirow{3}{*}{ PEE } & \multicolumn{8}{|c|}{ NHA Apgir } \\
\hline & \multicolumn{2}{|c|}{$0-3$} & \multicolumn{2}{|c|}{$4-6$} & \multicolumn{2}{|c|}{$7=10$} & \multicolumn{2}{|c|}{ Totd } \\
\hline & Jumlah & 4 & Jumlah & $\%$ & Jumah & 8 & Jamlah & 4 \\
\hline$(+)$ & 22 & 21,2 & 15 & 17,9 & 47 & 4 & $\$ 4$ & 100 \\
\hline$(-1)$ & 196 & 7,4 & 212 & 8,1 & 2225 & 84,5 & 2613 & 101 \\
\hline
\end{tabular}

Theal 7. Selarin Berat Lahir Bayi dari Ibu PEE (+) dengan PEE (-)

\begin{tabular}{|c|c|c|c|c|c|c|}
\hline \multirow[t]{2}{*}{ Berar bhir (gram) } & \multicolumn{2}{|c|}{ PEE I+) } & \multicolumn{2}{|c|}{ PEE \{\}} & \multicolumn{2}{|c|}{ Tbal } \\
\hline & Jn! & \% & $\mathrm{Jml}$ & 5 & Jml & 4 \\
\hline -240i & 28 & 33,9 & 38.1 & 14,6 & 412 & 152 \\
\hline$>2500$ & 56 & 65,7 & 2249 & 85,4 & 2305 & 84.8 \\
\hline Jumlah & 84 & 100,0 & 2633 & 100,0 & 2717 & 1000 \\
\hline
\end{tabular}


Suri Puduri, Ve. 9, No. 1, Jani 2001

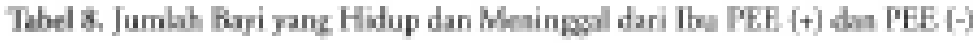

\begin{tabular}{|c|c|c|c|c|c|c|}
\hline \multirow[t]{2}{*}{ Besn Lhir brom, } & \multicolumn{3}{|c|}{ PLI $(+)$} & \multicolumn{3}{|c|}{ PEE t? } \\
\hline & Hidup & Mari & 9 & Hidup & Mari & M \\
\hline 4500 & 4 & 7 & 22,6 & 319 & 65 & 169 \\
\hline$m 2500$ & 49 & 4 & 7,6 & 2194 & 5 & 2,5 \\
\hline Jumbh & 7 & 11 & 13,1 & 251 & 13 & 4.5 \\
\hline
\end{tabular}

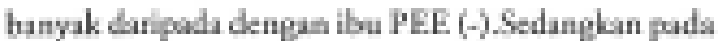

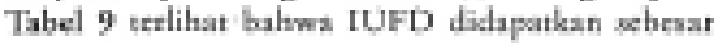
40\%. dan penyobib mortaliras rerbangh ialah pneumonia $(20 \%)$

\section{Diskugi}

Angka krjwian PEE di RSUP Banado tahan 195 dalsh 3,1 14. Precklanpsia dan aklampia veruma menyerang nullipars, kercntanannpe rertingai poda umur hang modk dan tua. Golongan yng tua

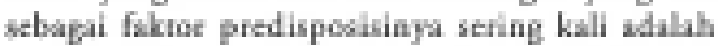
penyakit hiperiensi kronis, actanjtatin polongan primigravida moda jega ralatif labih renian dan shagai fiktor penytubny dikatakn karen kurang baiknje ane cidak pernah dilakuku perewan atenaril."

Bula pesician in PEE terbanyak diandan

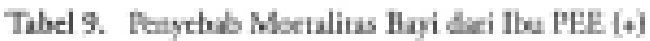
Han FEE (h)

\begin{tabular}{|c|c|c|c|c|}
\hline \multirow{2}{*}{$\begin{array}{l}\text { Prytub } \\
\text { Martitis }\end{array}$} & \multicolumn{2}{|c|}{ PEE L+) } & \multicolumn{2}{|c|}{ FEE (H) } \\
\hline & fumlih & 5 & Juthlah & 5 \\
\hline Allist & - & - & 5 & 4,7 \\
\hline Fnoummia & 3 & 26 & 21 & 17,2 \\
\hline HML & 1 & 6.7 & 6 & 4.7 \\
\hline TTh & 1 & 6.7 & $=$ & In \\
\hline FE & 1 & 6,7 & 3 & 2,3 \\
\hline Sppin & 2 & 13,3 & 16 & 12,5 \\
\hline Hipplibma & - & - & 4 & 2,3 \\
\hline Fribahan & 1 & 6,7 & 8 & 1,6 \\
\hline Curar bowin & - & - & 1 & 0,6 \\
\hline MFDF & fi & 40 & 1 & 53,9 \\
\hline Jankis & IS & 100,0 & $12 \mathrm{~h}$ & 10,0 \\
\hline
\end{tabular}

pada krlompak umer $30-34$ ahun 127.976 dan pada primgravida yairu 33,25. Perubahan banpa plasenra pada pre-aklampsia sudah banyk dinyatakn oleh para athi. Fungai plasenca lebih banyak menurun pado kadkan yeng hoolk, dan

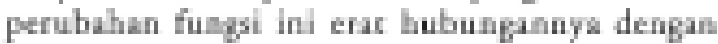

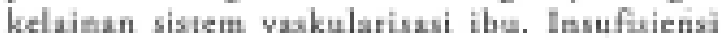
plasta depa manplibatan patumbuhan janin tentamkar ahirge injadi byil vang knil untuk

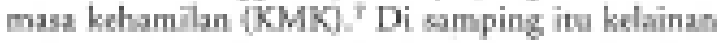
pada meonatus dapar pula diacbabkin sleh obs:

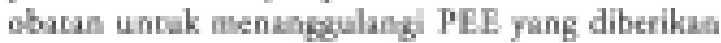
kepad ibu hamil, hurna semea obar PER umung dapai melilui placnia. Penparuh gang gosta pula pratampia islah labih buanye propeni byi yang lahir preserm, partambahan janin terhambat.

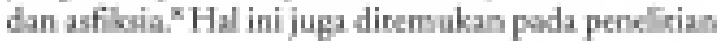
Lit yang medapaken bayi-bayi yang lahir dari ibu

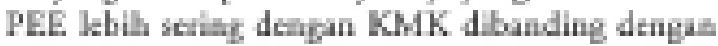
thu gang tilak tenderita PEE [Tahd in.

Poncliti hin melapurkar hy yang lahir tari thu pro-thmpia terat rata-raia mempunai brat lahir rendat, nilai Apger merit ke-5 pang rendah, angha indrom game napas dan kemanan perinend yong.

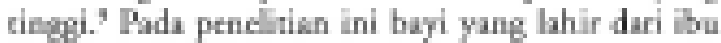
PEE dengin nili Apgin Q26,25 dan nila Apjar 46 bafilsia rimpan salared

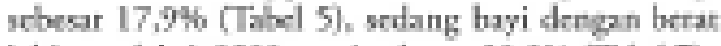

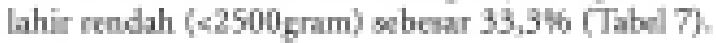

Kemarian perinatal jug ringsi pada pre.

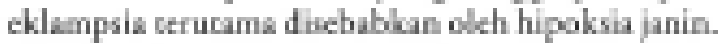
Hipolsia janis amut erat hubuegienya dengin

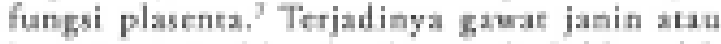
kemaran jain dalam kndungan diwhabson oleh

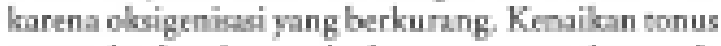
urenedan hcphon tohodup rangargan dapur pula

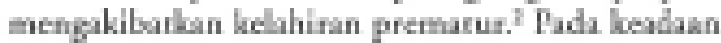

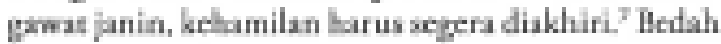
kaigar dilakukan bila ada knotraindikasi untuk 
melakukan induksi persalin*an *tru waktu dilakukan induksi persalinan timbul gawat janin. " Di samping itu penderita PEE mungkin mendapat obat-obatan untuk PEE seperti diazepam yang dapat menyebabkan depresi pernapasan pada bayi sehingga bayi harus dilahirkan dengan melakukan tindakan persalinan seperti ekstraksi cunam, ekstraksi vakum atau bedah kaisat. Pada penelitian ini tampak bahwa persalinan dengan bedah kaisar pada ibu PEE(+) jumlahnya lebih banyak bila dibandingkan dengan ibu PEE (-) (Tabel 0). Insiden bedah kaisar meningkat pada grup pre-eklampsia, Banias dkk. dalam penelitiannya mencatat bedah kaisar sebanyak $84 \%$ pada pre-eklampsia yang secara bermakna lebih tingggi daripada grup kontrol.’

Seperti telah dikemukakan bahwa PEE ridak hanya menyebabkan bayi KMK akan tetapi juga bayi prematur/imatur (Tabel 6), dengan segala morbiditasnya; misalnya kesukaran dalam mengarur suhu tubuh karena bayi mudah kehilangan cairan dalarn jumlah yang banyak sebagai akibat dari kurangnya lemak subkutan dan luasnya permukan rubuh bila dibandingkan dengan berat badan.

Sindrom gawat napas dapat disebabkan karena bayi prematur/imatur mengalami kekurangan surfaktan di dalam parunya, Gould dkk. melaporkan 25 bayi dengan percepatan marurasi paru (lesitiol spingo mielin $>2$ pada masa gestasi < 32 minggu), 5 Pada bayi kecil ini refleks menghisap dan menelan serta refleks batuk masih lemah sehingga mudah terjadi aspirasi pneumonia. Vasospasme pada hipertensi larena ketidakseimbangan prostasiklin tromboksan yang mengakibatkan berkurangnya aliran darah intervilli, dan gangguan pertumbuhan janin. ${ }^{*}$ Dalam penelician ini $40 \%$ kematian bayi dari ibu PEE adalah IUFD disusul dengan pneumonia sebesar $20 \%$. Pada penelitian ini tampak pula kejadian IUFD yang cukup tinggi yzitu $53,91 \%$ pada ibu tanpa PEE (Tabel 9), hal ini mungkin disebablcan karena perawatan antenatal yang kurang baik.

Infeksi pada bayi baru lahir mudah terjadi karena aktivitas imunologik humoral dan selular masih kurang, Bayi hanya dapar mengharapkan IgG ibu yang dapat melalui plasenta untuk mengatasi infeksi. Pengaruh obat-obatan untuk menanggulangi PEE yang diberikan kepada ibu dapat mengakibatkan bayi menderita gangguan pernapasan, bipotonia, dan malas minum. Hal lain yang perlu diperhatikan adalah pemantauan jangka panjang untuk tumbuh kembang bayi dari ibu penderita PEE pada umumnya.

\section{Kesimpulan}

- Primigravida lebih banyak menderita PEE daripada multigravida.

- Ibu penderita PEE mempunyai kemungkinan 4,4 kali lebih sering melahirkan bayi KMK dari pada ibu tanpa PEE.

- Ibu dengan PEE Iebih sering mengalami persalinan dengan tindakan dan bayi yang dilahirkan lebih sering dengan asfiksia berat.

- Ibu dengan PEE lebih sering melahirkan bayi dengan berat lahir rendah ( $<2500 \mathrm{gram})$ dan angla kematiannya lebih tinggi-

\section{Daftar Pustaka}

1. Moore MP, Benny PS. Pre-eclampsiz. J Podiate Obstex Gynaecol 1995; 15:14-7.

2. Hoedjang RF. Neonarus dari preeklampsia dan eklampsia di RSCM pade tahun 1991. Disampaikan pada Seminar dan lokekarya penanganan preeklampsia das eklampia, Jakarta 16 Januari 1993.

3. Wibraw B, Rachimhadi T. Preeklampsia dan eklampsia. Dalam: Wiknjesastro $\mathrm{H}$, Saifuddin AB, Rachimhadi T. Ilmu Kebidanan, edisi loc-3. Jakarta: Bina Pustaka 1991; 281-300.

4. Wiknjosastm G. Syuib A. Penanganan hipertensi dalam kehamilan. MKI 1987; 37:159-61.

5. Kim CR, Vohr BR, OH W. Effect of maternal preedampia on brain-sem auditory erobed respoes in very low birth wright infants. J Pediatr 1995; 127:123. 7.

6. Koemarsono B. Tinjwaan hasil pengelelaas proekbarajua berat/eklanapsia dengan menggunahan panduain saigas gesetoxis POKGI di RSU Gunung Wenang Manado 1992 . 1993. Trais. Bandung: Lah/UPF Cbsecri dan Ginekologi FK-UNPAD/RSU Dr. Hasan Sadikin, 1993

7. Wiknjosastro G. Pengamasan jaain pada pee-eklampaia. MKI 1987; 37;162-4.

8. Wiknjocastro G. Saifuddin AB. Pemantauan janin pada precldampaia-eklampais. Disampaikan pada seminar dan lokakarya penanganas pereklampsia dan eklampsiz. Jakarta 16 Januari 1993. 
Sari Pediatri, Vol. 3, No. 1, Juni 2001

9. Banias BB, Dewoe 1D, Nolan TE, Severe peredampsia in preierm prognancy between 26 and 32 wrok pestation. Am J Perinanol 1992, 9.357.9.
10. Handaya. Penanganan pre-eklampsia berat dan eklampsia, MKI 1987; 137:1. 